\title{
What is Mathematics, Really? Who Wants to Know? ${ }^{1}$
}

\section{O que é Realmente a Matemática? Quem Quer Saber?}

\author{
Michael Friedrich Otte* \\ Luiz Gonzaga Xavier de Barros**
}

\begin{abstract}
Famous physicists, like Einstein and Wigner have been wondering, why mathematical symbolism could play such an effective and decisive role in the development of physics. Since the days of Plato, there have been essentially two different answers to this question. To Plato mathematics was a science of the unity and order of this universe. Since Galilei people came to believe that mathematics does not describe the objective world, it is not a reflection of some metaphysical realism. It is rather a reflection of human activity in this world. Kant, by his "Copernican Revolution of Epistemology" seems to have been the first to realize this. For example, number, or more generally arithmetic, was to the Pythagoreans "a cosmology" (KLEIN, 1985, p. 45), to Dedekind it is a means to better distinguish between things. The paper sketches the transition from an ontological to a semiotic interpretation of mathematics.
\end{abstract}

Keywords: Mathematics. Mathematics Education. Philosophy of Mathematics. Epistemology. Cognition. Semiotics.

\section{Resumo}

Físicos famosos, como Einstein e Wigner, perguntaram-se por que o simbolismo matemático desempenha papel tão decisivo e efetivo no desenvolvimento da física. Desde a época de Platão, duas diferentes respostas a essa questão foram dadas. Para Platão, a matemática era uma ciência da unidade e da ordem deste universo. Com Galileu surge a crença de que a matemática não descreve o mundo objetivo nem é reflexo de algum realismo metafísico: é, ao contrário, um reflexo da atividade humana no mundo. Kant, com sua "Revolução Copernicana da Epistemologia", parece ter sido o primeiro a perceber isso. Por exemplo, para os pitagóricos, o número - ou, de forma mais geral, a aritmética - era "uma cosmologia" (KLEIN, 1985, p. 45), já para Dedekind, o número era apenas um meio para distinguir coisas. Este artigo tenta compreender, esquematicamente, a transição de uma interpretação ontológica para uma interpretação semiótica da matemática.

Palavras-chave: Matemática. Educação Matemática. Filosofia da Matemática. Epistemologia. Cognição. Semiótica.

\footnotetext{
${ }^{1}$ This article is based in a plenary presentation at the International Colloquium in Honor to Michèle Artigue, Paris, May 2012.

" $\mathrm{PhD}$ in Mathematics (Universität Göttingen/UG - Germany); Universidade Anhanguera de São Paulo (UNIAN), São Paulo, SP, Brasil. Programa de Pós-graduação em Educação Matemática. E-mail: michaelontra@aol.com.

** $\mathrm{PhD}$ in Mathematics (Universidade de São Paulo/USP - Brazil); Universidade Anhanguera de São Paulo (UNIAN), São Paulo, SP, Brasil. Programa de Pós-graduação em Educação Matemática. E-mail: lgxbarros@ hotmail.com.
} 


\section{A question}

The first part of our title has been copied from Reuben Hersh's book whose title is What is Mathematics, really? (HERSH, 1997). We shall try to develop a context that might shed some light on the question.

Like Hersh, the majority of philosophers and common people consider the question In what sense do mathematical objects exist? the main problem in the philosophy of mathematics. Until about 1800, Hersh says, western philosophy believed that there were two kinds of things in the world: mental and physical. Hersh thinks that mathematics shows the inadequacy of this belief and he proposes instead to consider mathematical objects as social entities and to acknowledge that mathematics is essential a social reality. Hersh wants to avoid the alternative of mentalism vs. empiricism. Social entities, he says, "are neither mental nor physical, but they have mental and physical aspects" (HERSH, 1997, p. 14). Hersh claims, in fact, that questions about the nature of mathematical objects can be answered from a social perspective only.

In return, you might as well say that questions about the objects of mathematics in general come up only when one considers mathematics from a social perspective, rather than from a cognitive or epistemological one. The individual mathematician asks questions and searches for answers to them, he solves problems and broods over puzzles, constructs proofs, invents methods, runs into ideas and becomes fascinated by them, but he rarely bothers to define what a mathematical object is, nor would he care to ask what mathematics itself is. Jean Dieudonné, protagonist and main spokesperson of Bourbaki group, had once characterized the position of this group of mathematicians by their lack of ontological commitment. He described Bourbaki's attitude towards the problem of the foundations of mathematics as marked by total indifference. The notion of structure and structural form and the axiomatic method were, however, very important to Bourbaki's approach and provided, in fact, a connecting link within the group. (DIEUDONNÉ, 1983).

It is only as soon as we pass from the context of discovery to the context of communication and justification that questions of this kind come up.

An example from the struggles during the Industrial Revolution of the $19^{\text {th }}$ century and its social repercussions. Eugen Dühring $(1833$ - 1921) was a German economist and a social democrat, who was a strong critic of Marxism. He is chiefly remembered because of Friedrich Engels' criticism of his views in Anti-Dühring: Herr Eugen Dühring's Revolution in Science. 
Among other things, Dühring had written that in pure mathematics the mind deals with its own free creations and imaginations. The concepts of number and figure are the adequate object of that pure science which it can create of itself, and hence it has a validity which is independent of particular experience and of the real content of the world.

Engels answered:

(...) it is not at all true that in pure mathematics the mind deals only with its own creations and imaginations. The concepts of number and figure have not been derived from any source other than the world of reality. The ten fingers on which men learnt to count, that is, to perform the first arithmetical operation, are anything but a free creation of the mind. Counting requires not only objects that can be counted, but also the ability to exclude all properties of the objects considered except their number - and this ability is the product of a long historical development based on experience. Pure mathematics deals with the space forms and quantity relations of the real world - that is, with material, which is very real indeed. The fact that this material appears in an extremely abstract form can only superficially conceal its origin from the external world.

We shall not enter in the discussion at this moment, but should remind ourselves of just two things. First, this dispute about the nature of the objects of mathematics and or about was a part of a political and social discussion. Second, both disputants addressed the question on quite different levels of generality. Dühring relates to the individual experience and reflection of the mathematician, while Engels addresses the question from the point of view of socio-cultural development. Dühring is not at all interested in the objective foundations or the nature of mathematical objects, while these are Engels only concern. One might say one of them refers to the context of individual discovery, the other to the context of general justification.

\section{Another question}

Hersh's problem thus provokes the next question: What is human society really? Simply calling something social does not help to overcome the dichotomy between materialism and idealism that did not satisfy Hersh. The answers to our second question: What is human society really? have been commonly framed, since the Industrial Revolution, in terms of two alternative schemas of comprehension: the paradigm of communication and the paradigm of production (MARKUS, 1986, p. 12). One of the two paradigms considers the historicity of mathematics as essentially being the history of its languages and means of 
communication, the other makes that history dependent on the means of construction and of self-reproduction of man as part of natural history. "Whether the relations of intersubjectivity are modeled on those pertaining to linguistic communication or on the interaction of individuals in the reproduction of their material livelihood - this choice has not only theoretical consequences" (MARKUS, 1986, p. 12). The dispute between Engels and Dühring provides a pertinent example here.

That types of production do profoundly influence all ways of social and cultural life seems a commonplace. But differences in the mode of communication are often as important as differences in the mode of production, for they involve developments in the creation and storing of human knowledge. Although they are not directly productive, they could form an indispensable integrative part of the system of production.

Therefore, these different paradigms concerning the foundations of social coherence are related to quite a cluster of interesting distinctions and alternative conceptions about man and culture, the relation of mathematics to language or to its possible applications, with different philosophies of mathematics and with various logical and epistemological visions. For instance, considering mathematics a language is not only very common in math education, but also determines pure mathematics as a social-institution and, in consequence, analytical philosophy of mathematics too holds mainly views that seem exclusive to the communication paradigm of social coherence.

Another influence of the difference between the paradigm of communication and the paradigm of production, which may interest us here, lies in their different views of symbolization. If one believes like Locke that language is "the great instrument and common type of society" (LOCKE, 1975, p. 254), one might also follow him in the view that signs are essentially determined by the human subject, who employs them to represent the ideas he has in mind. From the perspective of the individual's interaction with the objective world, however, signs are essentially determined by their objects, like the smoke that indicates the fire, or the footprint on the beach that informed Robinson Crusoe of the arrival of another human being on his lonely island. Alternatively, think of the vertices of diagram. A system of coordinates in the plane is an example: one has to mark three adequately chosen points directly and the rest may then be described indirectly and in relations to the three initial points. Mathematics is more like a technology, than like a language.

In addition, if taken at face value, mathematics makes existential assertions: it asserts for instance that there exist prime numbers greater than a million, and therefore that there 
exist numbers. So, to argue against the idea that mathematics is true by logic and language alone, we only need argue that you cannot get existential assertions out of logic and definitions alone. Kant did provide such an argument in his Critique of Pure Reason (B 622627) and this argument is rather persuasive.

So to one group the conventional symbol or word is the paradigmatic sign, while to the other, it is the index. Since mathematics cannot do without indexical signs, as Kant was emphatic to point out in his Critique of Pure Reason (B 742), while common language does not have indexical signs, it seems plausible that mathematics be essentially an activity, a symbolic technology. According to Hilbert, there is a privileged part of mathematics, which relies only on a purely intuitive basis of concrete signs. Whereas the operating with abstract concepts was considered inadequate and uncertain, there is a realm of extra-logical indexical signs which fulfill their semiotic function by being directly present in our experience. This view corresponds to Hilbert's famous Am Anfang ist das Zeichen (At the beginning there is the token).

Formal axiomatic, in its first stages, denied that mathematics needs objects. Mathematics is just hypothetic-deductive reasoning from postulates. Peirce saw, however, "as no one before him had, that indication (pointing, ostension, deixis) is a mode of signification as indispensable as it is irreducible" (SEBOEK, 1995, p.223). That mathematics, on the one hand, does not make existential claims, only outlining possibilities and in the other hand makes essential use of indices, in order to represent statements of fact, is fundamental for Peirce's conception of mathematics as diagrammatic reasoning.

Peirce writes:

One might think, that there would be no use for indices in pure mathematics, dealing, as it does, with ideal creations, without regard to whether they are anywhere realized or not. But the imaginary constructions of the mathematician, and even dreams, are so far approximate to reality as to have a certain degree of fixity, in consequence of which they can be recognized and identified as individuals (PEIRCE, CP 2.305).

The indices occurring in pure mathematics refer to entities or objects that belong to a model, rather than to "the real world", that is, they indicate objects in constructed semantic universes.

Strictly formalistic mathematics, as it was developed by Hilbert's school, did at first not "pay sufficient attention to all that burden of set-theoretic tools which were strictly connected with axiomatics and which can be summarized in the word "model"' (CASARI, 1974 , p. 52). 
Axiomatic mathematics, structural mathematics or mathematics as diagrammatic reasoning represents a genetic perspective aiming at generalization, - always in in connection with new mathematical applications - whereas mathematics as arithmetic or set theory is mainly concerned with foundations and rigorous proofs. Norbert Wiener says about this period:

He who concentrates on his own mental states will concentrate, when he becomes a mathematician, on the proof of mathematical theorems, rather than on the theorems themselves, and will be compelled to object to inadequate proofs of adequate theorems. (...) The new mathematics devoted itself to rigor (WIENER, 1951, p. 92).

To this distinction in the development of pure mathematics corresponds a distinction in the conception of logic, which Heijenoort had pointed out: Logic as a lingua universalis versus Logic as a calculus ratiocinator (HEIJENOORT, 1967).

Frege, for example, considered logic as universal and as a language, rather than as a part of an algebraic calculus or a formal system in the sense of Boole, Grassmann, Peano and Peirce or Schroeder. Frege`s universal conception "of logic expresses itself in an important feature of Frege's system. As is well known, according to Frege, the ontological furniture of the universe, divides into objects and functions", (HEIJENOORT, 1967, p. 234). The other conception of logic does not know of the notion of a fixedly given universal ontology, but refers to the elements of some model world. The ontology can be changed at any time. The universe of discourse comprehends only what we agree to consider at a certain time, in a certain context.

The arithmetization of mathematics (Bolzano, Cauchy, Weierstrass, Kronecker or Poincare) became important in particular to the $19^{\text {th }}$ century educational context. The view of mathematics as a formal language has been particularly prominent in education and it characterizes the attempts to teach students how to use a coherent system of mathematics. In educational contexts, problems play an auxiliary and instrumental role only. We do not, says Effros, "include algebra in the high school curriculum in order to enable students to solve word problems" (EFFROS, 1998, p. 135). In addition, the pedagogical principles underlying mathematics instruction are quite similar to those used in language instruction (EFFROS, 1998).

\section{A first answer}


One answer to our initial question, quite familiar to contemporary pure mathematics, would be to say that mathematical objects are sets, sets of points, for example. The dominant trend of arithmetical rigor inaugurated by Bolzano, Cauchy, Dirichlet and others considered arithmetic as a universal language of mathematics and set theory a universal object field of mathematical objectivity. Without the theory of infinite sets, serving as a universal realm of reference to symbolic mathematics, the creation of pure mathematics would not have been possible.

Ferreirós (1999) asks why some $19^{\text {th }}$ century mathematicians consider set theory to be a part of logic. Both Dedekind and Frege make arguments that depend on moving from a concept to a set (concept extension). In the case of Dedekind, this was natural, or even necessary to develop his abstract and structural concept of algebra (of group theory, for example) and even more so to develop his foundations of arithmetic. And Frege, considered numbers to be extensions of certain concepts. In the sentence four horses moved the coach of the Queen, the number four has, according to Frege, to be understood as the extension of the concept horses that drew the coach of the Queen, or four objects fall under the concept horse harnessed to the coach of the Queen. Frege argues that numbers are objects and assert something about a concept (FREGE, 1884/1974).

And in order to ban the Principle of Continuity from mathematics, as Bolzano, Cauchy and modern analysis wanted it, in order to provide an adequate definition of a continuous function one has to arithmetize the continuum and mathematical functions had to be conceived of extensionally. In his Introductio in analysin infinitorum of 1748, Euler defined a continuous function of a variable quantity as an analytical expression composed in any way of that variable and constants (EULER, 1748, p. 4), such that "un simple changement de notation suffira souvent pour transformer une fonction continue en fonction discontinue, et reciproquement", as Cauchy did observe (CAUCHY, 1882, p. 145).

Cauchy, after having demonstrated the inconsistency of Euler's efforts, revised the whole approach, transforming mathematics into extensional theory. It became clear that a continuous mathematical function had to be conceived of as an equivalence class of concrete representations of it, rather than to be identified with some of its possible representations, the axiom of extensionality furnishing the constitutive equivalence relation. The property of being continuous can be attributed to such a class only, rather than being a property of some representation of a function. 
And, if we analyze Cauchy's definition of continuity, we may realize that the task of characterizing continuous functions is equivalent to choosing a topology, that is, choosing a class of open sets. The topology of a space is a property of its global structure and is therefore appropriately to be characterized in set theoretical and axiomatic terms. Without Cantor's set theory general topology and abstract measure theory would not have been possible. And the theories of measure and integration formed in turn for some time the most substantial single application of Cantorian set theory. It is no coincidence that the so-called Continuum hypothesis of set theory held the greatest importance for Cantor (OTTE, 2007).

In 1888, David Hilbert, a young man at the time, amazed the mathematical world with a novel and unexpected solution to Gordan's Problem about the basis of algebraic invariants. Gordan's problem was to show that all invariants could be expressed as combinations of a finite basis of invariants. Twenty years earlier, Paul Gordan had solved this problem for the two variable case by a laborious constructive method. Gordan had demonstrated the theorem of the finiteness of generators for binary forms using a complex computational approach. Attempts to generalize his method to functions with more than two variables failed because of the enormous complexity and difficulty of the calculations involved. Hilbert showed that having no finite basis would lead to a contradiction. A formal view of theory and a set theoretical ontology of pure mathematics were the prerequisites of such an indirect proof procedure. Hilbert therefore adopted and warmly defended Georg Cantor's set theory.

But, it took a while for the mathematical world to accept this indirect non-constructive argumentation, based exclusively on the requirement of logical consistency, as a valid solution. Gordon himself expressed dissatisfaction in the famous pronouncement This is not mathematics; it is theology. On the other hand, Felix Kline immediately accepted Hilbert's proof, describing it as wholly simple and, therefore, logically compelling. Skepticism about Hilbert's method did not last long.

Pure mathematics as a science of its own kind was made possible with the creation of Cantor's universe of infinite sets of arbitrary cardinality. And the comprehensive reform of mathematics education after the Sputnik shock of 1957, which came to be known under the name New Math, has tried to copy this development, which led to the establishment of pure mathematics on an elementary level. The reform had gloated at the affirmation that for the first time in the history of mathematical education, one was to succeed in reconciling intuition and logic, said George Papy in 1967 in an oral presentation at the Düsseldorf Academy of Sciences. Papy became deeply interested in improving the quality of mathematics education at 
the secondary school level, and assumed a position of leadership of what became known as the New Math. Elementary set theory was supposed to form a counterweight to the traditional notion of school mathematics as mere instrumental calculation and as a formal language.

To try and provide mathematical cognition with foundations sui generis was really a courageous undertaking. Even critics of the New Math, like R. Thom, pointed in the same direction indicating the importance of a graspable mathematical ontology. Thom in his invited lecture to the Second International Congress on Math. Education in Exeter in 1972 had said: "The real problem which confronts mathematics teaching is not that of rigor, but the problem of the development of meaning, of the existence of mathematical objects" (THOM, 1973, p. 206). Meaning and reference to objects are two different matters, however. And the problem was more on the side of concepts and their meanings, rather than with set theory. Papy's hopes must appear futile and unfounded as long as one does not develop an adequate answer to the question What is a concept? Thom too did not see that the main danger to mathematical education came from the prevailing empiricism and reductionism of everyday thinking.

\section{Conceptual thinking: substance versus function}

Concept formation and relational thinking seems to remain a key problem in school mathematics (SKEMP, 1978). Relational thinking, is the notion by which modern mathematics and science has been characterized, since Cassirer`s famous book, Substanzbegriff und Funktionsbegriff (Substance and Function) of 1910. But, relational thinking is the great obstacle of everyday knowledge, which tends to identify knowledge with reality. Therefore, the reform movement failed because of its empiricism and its insufficient understanding of concept formation and conceptual thinking. The reformers did not get beyond the elementary abstractive notion of a concept, a notion called in mathematics, definition by abstraction. A set would be than the extension of the concept of all read things, for example.

The Ernst Cassirer had in 1910 already criticized this type of abstractive concept formation. He wrote:

The chief features of this doctrine are well-known and do not need detailed exposition. Its presuppositions are simple and clear; and they agree so largely with the fundamental conceptions, which the ordinary view of the world consistently uses and applies, that they seem to offer no foothold for criticism. Nothing is presupposed save the existence of things in their inexhaustible multiplicity, and the power of the mind to select from this wealth of particular existents those features 
that are common to several of them. When we thus collect objects characterized by possession of some common property into classes (CASSIRER, 1910, p. 5).

However, Cassirer continues, "the concept would lose all value if it meant merely the neglect of the particular cases from which it starts, and the annihilation of their peculiarity". And he goes on:

There is nothing to assure us that the common properties, which we select from any arbitrary collection of objects, include the truly typical features, which characterize and determine the total structures of the members of the collection. (...) If we group cherries and meat together under the attributes red, juicy and edible, we do not thereby attain a valid logical concept, but a meaningless combination of words, quite useless for the comprehension of the particular cases(...) In his criticism of the logic of the Wolffian school, Lambert pointed out that it was the exclusive merit of mathematical "general concepts" not to cancel the determinations of the special cases, but in all strictness fully to retain them. When a mathematician makes his formula more general, this means not only that he is to retain all the more special cases, but also be able to deduce them from the universal formula. (...) Thus abstraction is very easy for the "philosopher," but on the other hand, the determination of the particular from the universal so much the more difficult; for in the process of abstraction he leaves behind all the particularities in such a way that he cannot recover them, much less reckon the transformations of which they are capable. This simple remark contains, in fact, the germ of a distinction of great consequence.

Mathematical concepts represent relations and functions, rather than merely classes of empirical objects. Since the days of Eudoxus, it has been clear to the mathematician that structural relations form the subject matter of applied mathematics. When an empirical quantity is measured by comparing it with a unit of the same type, the resulting number represents the relationship between both. One of the most important discoveries of the Pythagorean School is therefor without doubt that of the incommensurability between the side and the diagonal of the square. This implied not only the failure of arithmetization and was a rejection of the Pythagorean view that the realm of number provides a model of the entire natural world, but it also demonstrated the fundamental importance of relational thinking.

The rigor movement of arithmetization of the $19^{\text {th }}$ century could succeed only if it generalized the number concept itself. When by the end of the $18^{\text {th }}$ century the importance of the relationship between the notions of function and of continuity, became more clearly perceived and the basic property of an abstract mathematical function became realized in terms of its continuity, the function concept had to be generalized. Since Bolzano or Cauchy, mathematicians considered curves as point sets, rather than conceiving of them in analytical 
terms as formulas, because the number of possible functions was much larger this way. Now the number concept had to be generalized and enlarged accordingly by creating the real and complex numbers, to successfully arithmetize the continuum and make the approach work. This proved not to be possible in a constructive way, however, but had to be done axiomatically.

The axiomatic method of Hilbert and Noether is, in fact, nothing but the highest point of relational thinking in mathematics and it began to enter first year university classrooms in Germany only some years after World War II. We still remember the enthusiasm with which we received the first edition of Graeub’s Lineare Algebra (Linear Algebra) published in 1958, and its coordinate free treatment, after having been accustomed to the tedious and clumsy calculations in terms of coordinates and matrixes of the traditional approach. However, the weaker or more conservative students and those from physics did not readily follow Graeub's axiomatic and structural presentation. These students wanted direct calculations and elementary proofs, that is, proofs that were maximally self-contained. Such proofs should reveal a theorem true by the light of the very terms that contain it, analytically true. No conceptual constructions or additional intuitive hypotheses should be required. R. Skemp had called this type of thinking, instrumental understanding, and had contrasted it with what he called relational understanding (SKEMP, 1978).

Relational thinking is the notion by which modern mathematics and science has been characterized, since Cassirer`s famous book, Substanzbegriff und Funktionsbegriff (Substance and Function) of 1910. But, relational thinking is the great obstacle of everyday knowledge, which tends to identify knowledge with reality. Therefore, the reform movement failed because of its empiricism and its insufficient understanding of concept formation and conceptual thinking.

\section{From Euclid and Kant to Bolzano and Hilbert}

Historically speaking, Euclid's Elements, of course, cannot be interpreted as a formal system in Hilbert's sense. The hypotheses or assumed premises are here to be seen as admissible or conceded constructions,_rather than as formal propositions. In Euclid's geometry the stipulated possibility to perform a certain construction leads as a consequence to the possibility of other constructions and this possibility is to be found out by a kind of thought experiment. . It is assumed, for example, the possibility to draw a straight line from 
any point to any point (Postulate 1.); or: to describe a circle with any center and distance (Postulate 3.). And then, the theorems say in essence, If I can construct $A$, then $B$ too. For example theorem 1 of Book one: On a given straight line segment to construct an equilateral triangle.

Descartes and Newton understood Euclid in this manner. Kant's views too were very similar to Euclid's, and it has with some justification been claimed, in fact, that Kant's Critique of Pure Reason tried to accomplish a Newtonian revolution in philosophy, rather than a Copernican one (HAHN, 1988).

Kant assumes that all our knowledge-extending cognitions are synthetic. A new light (Kant) must have flashed on the mind of people like Thales, when they perceived that the relation between the length of a flagpole and the length of its shadow enables one to calculate the height of the pyramid, given the length of its shadow. "For he found that it was not sufficient to meditate on the figure as it lay before his eyes, (...) and thus endeavor to get at knowledge of its properties, but that it was necessary to produce these properties, as it were, by a positive a priori construction" (KANT, 1787/1929).

And indeed, the flagpole in itself has no specific relationship whatsoever to the pyramid as such. This implies, according to Hume or to Kant, that there do not exist a priori reasons to assume that laws must spring from the things related. Kant, having the constructivism of Euclidean geometry in mind, gives preference to the synthesis of the mind.

Kant considered mathematics a constructive activity and reflective abstraction (Peirce, Piaget) its mode of processing. The synthetic unity of consciousness, according to Kant, is "an objective condition of all knowledge. (...) For in the absence of this synthesis, the manifold would not be united in one consciousness" (KANT, 1787, B 138). When we speak for example of a general triangle in geometry, generality, Kant says, does not result from the particular figure as such, which is an individual intuition only, but results from the fact that "we keep our eye merely on the act of the construction of the concept" (KANT, 1787, B 742). In this manner space becomes a means of mathematical activity and cognition, rather than being some objective entity.

Salomon Bochner identified reflective abstraction and thought experiments as the foundations of the new mathematics of the Scientific Revolution of the $17^{\text {th }} / 18^{\text {th }}$ centuries. He writes:

In Greek mathematics, whatever its originality and reputation, symbolization ... did not advance beyond a first stage, namely, beyond the process of idealization, which is a process of abstraction from direct actuality, (...) However (...) full-scale 
symbolization is much more than mere idealization. It involves, in particular, untrammeled escalation of abstraction, that is, abstraction from abstraction, abstraction from abstraction from abstraction, and so forth; and, all importantly, the general abstract objects thus arising, if viewed as instances of symbols, must be eligible for the exercise of certain productive manipulations and operations, if they are mathematically meaningful (BOCHNER, 1966, p. 18).

Everybody understands this process of reflective abstraction differently, however, and these differences depend on whether one thinks of the observation of one's own movements and structures in space thereby created (diagrammatic reasoning!), or whether one looks statistically at the experiences with sets of similar cases. For example: With so and so many patients of a certain type of symptoms the treatment with agent $X$ has helped, etc., etc.. MD G. House, protagonist in a well received TV-series, works in his diagnosis clinic on such a basis of statistical experience. The empiricist camp within the philosophy of mathematics thinks this way about mathematics and its applications. John Barrow (1992) writes, for example, characterizing this philosophical position:

\begin{abstract}
We invent mathematics, we do not discover it. (...) The reason we find mathematics so useful is from this point of view merely an indication of how little is known about the physical world. It is only the properties well suited to mathematical description that we have been able to uncover. (...) This position is more likely assumed by consumers of mathematics rather than by mathematicians themselves. The great number of books titles like Mathematical Modelling of Hydrodynamic Phenomena, etc., is an expression of this position. A hundred years ago, authors might have written Theory of .... instead (BARROW, 1992, p. 50)
\end{abstract}

And Barrow comes to mention Kant's constructivism as the source of this opinion. He says: So if we see the universe to be mathematical, this does not mean that it really is mathematical, any more than the sky is pink because it looks that way when we wear rosecolored spectacles.

Gottfried Martin too has related the two sides of the development of modern mathematics - the axiomatic versus the arithmetical - to the differences between Kant and Bolzano:

One can characterize the difference between Kant and Bolzano meaning that for Kant axiomatization, and that for the Bolzano arithmetization has been the ultimate goal. Felix Klein is right, when he says: 'Bolzano is one of the fathers of the 'arithmetization' of our science'. By the keywords arithmetization and axiomatization the viewpoints are given for a specific assessment of the researchers involved in these investigations. These viewpoints also make understandable, Hilbert's appreciation of Kant, on the one hand, and Couturat's, on the other (MARTIN, 1956, p. 108).

In general and independently of the differences just mentioned, mathematics and the sciences now come to construct theories, fictions, small boats on the fathomless ocean of objective reality that at any moment can go down and get drowned again. We become creative 
in our efforts as mathematicians, as Barrow had observed, because so little is known about the world at large.

The only requirement of a mathematical theory is its logical consistency and formal proofs are the only means of its development and progress. Ultimately, a theory is a formal structure whose various elements are connected by purely formal arguments. Consequently, despite all his successes, the nature of Hilbert's non-constructive proof, mentioned above, stirred up more trouble than Hilbert could have imagined at the time. Hilbert would later respond to his critics many different constructions are subsumed under one fundamental idea - in other words (to quote Reid): Through a proof of existence, Hilbert had been able to obtain a construction; the proof (i.e. the symbols on the page) becomes the object (REID, 1970). The axiomatic movement as anticipated in the work of Poncelet or Grassmann, tried to employ, so to say, a top-down strategy, solving the foundational problems of mathematics by extending and generalizing its relational structures and its rules of inference. Grassmann's dropping of the commutativity of a general product and his definition of the anti-commutative vector product provides a pertinent example here.

Theories became forms, that is, became now recognized as realities in their own right, because of the wide range and great diversity of intended applications (be they mathematical or non-mathematical). David Hilbert made a remark "which contains the axiomatic standpoint in a nutshell: It must be possible to replace in all geometric statements the words point, line, plane by table, chair, mug" (REID, 1970, p. 264).

Axiomatic thinking is thinking about form and form must be constructed and idealized. Hilbert's remark is usually interpreted as expressing the tendency towards a deontologization of modern axiomatized mathematics. This is not so. Any formal theory has various intended applications or non-isomorphic models, and what the axioms describe are classes of objects rather than particular objects themselves. In this respect, mathematical axioms resemble natural laws. And like the latter, they have to be supplemented by an indication of the domain of objects to which they apply. And this is what Hilbert meant! (see for example: David Hilbert 1970, Gesammelte Abhandlungen, Bd. III, Springer Verlag Heidelberg, pp 378ff.)

Axiomatic theories are intensional: the axiomatic schemata define concepts, not objects, whereas set-theoretic mathematics is extensional. Both aspects are complementary to each other. This comes out very clearly when we look at Peano's axiomatization of arithmetic. On two counts, Russell says, for example, Peano's approach 
fails to give an adequate basis for arithmetic. In the first place, it does not enable us to know whether there are any sets of terms verifying Peano's axioms. ... In the second place.... we want our numbers to be such as can be used for counting common objects, and this requires that our numbers should have a definite meaning, not merely that they should have certain formal properties (Russell, 1998, p. 10).

And further:

If we start from Peano's undefined ideas and initial propositions, arithmetic and analysis are not concerned with definite logical objects called numbers, but with the terms of any progression. We may call the terms of any progression $0,1,2,3, \ldots$, in which case $0,1,2$, become 'variables'. To make them constants, we must choose someone definite progression; the natural one to choose is the progression of finite cardinal numbers as defined by Frege (RUSSELL, 1954, p. 4).

So set-theoretical models and axiomatic systems jointly represent the essential complementarity of extensional and intensional aspects of mathematics. But, this has so far hardly been recognized.

\section{Conclusion}

To ask questions, like, What is Mathematics, really? Belongs to the business of the philosopher. The philosopher does not answer the question in a definite manner because philosophy, says Deleuze, "is the discipline that involves creating concepts" (DELEUZE \& GUATTARI, 1994, pp. 5-8). Concepts are very different from definitions. Definitions are formulated in order to draw conclusions and to solve problems. Definitions are cognitive and communicative functions, in the first place. Concepts, in contrast, represent perspectives on reality. They are like visions of possibilities. The concepts occurring in mathematics are relatively simple, but mathematical reasoning is very intricate as a rule.

Therefore mathematical or logical definitions are difficult to understand. Think of the Cauchy-Riemann definition of a continuous function with its interlaced quantifiers! Therefore a semiotic conception of mathematics, conceiving it, as diagrammatic reasoning might prove useful, as much to the philosophy of mathematics as to mathematics education. Semiotics, conceived of in terms of a complementarity of meaning and reference, should become a fundamental research instrument to understand mathematical cognition and epistemology.

School mathematics is, in fact, essentially algebra. However, algebra is treated in school as a language that thinks largely for itself, like a computer language. "Frequently, students are instructed that they must think about things in order to understand them and to move forward. But in some sense, the greatest progress of human thought have incurred as a result that we have learned to do things without thinking" (BARROW, 1992, p. 3). 
Now, the essential fact, responsible for both, mathematics not being simply and straightforward algorithmic knowledge and humans not being just calculators, refers to the necessity of idealization and generalization. We must create new concepts and ideas, or ideal objects. To generalize means just this: to introduce new ideal objects.

\begin{abstract}
The human contribution to the miracle of life around us is obvious. We hit upon new ideas, on the fly, all the time and we have been performing this magic for, at least 50,000 years. We did not make galaxies, we did not make life. We did not make viruses, the sun, the DNA, or the chemical bond. But we do make new ideas (TURNER, 2014, p. 1).
\end{abstract}

\title{
References
}

BARROW, J. D. Perche il mondo e matematico?. Roma: Editore Guis, 1992

BOCHNER, S. The Role of Mathematics in the Rise of Science. Princeton: Princeton University Press, 1996

BOCHNER, S. Mathematical Reflections. The American Mathematical Monthly, Washington DC, v. 81, p. 827-852. 1974.

CASARI, E. Axiomatical and Set-Theoretical Thinking. Synthese, New York: Springer. V. 27, p. 4961. 1974.

CASSIRER, E. Substanzbegriff und Funktionsbegriff. Berlin: Verlag Bruno Cassirer, 1910

CAUCHY, A. L. Euvres complètes d'Augustin Cauchy. Paris: Gautier-Villar. Série 1, tome 8, 1882.

DELEUZE, G \& GUATTARI, F. What is Philosophy?. Translation by TOMLINSON, H. \& BURCHELL, G. New York: Columbia University Press, 1994.

EFFROS, E. G. Mathematics as Language, In: DALES, H. G. \& OLIVERI, G. (Ed.). Truth in Mathematics. Oxford: Oxford University Press, 1998. p. 131-146.

ENGELS, F. Herrn Eugen Dührings Umwälzung der Wissenschaft. Leipzig: GenossenschaftsBuchdruckerei, 1878.

EULER, L. Introductio in analysin infinitorum, Heidelberg: Springer, 1748.

FERREIRÓS, J. Labyrinth of Thought: A History of Set Theory and its Role in Modern Mathematics. Basel: Birkhäuser Verlag, 1999

FREGE, G. Die Grundlagen der Arithmetik. Breslau: W. Koebner, 1884. English translation in FREGE, G. The Foundations of Arithmetics. Evanston, Illinois: Northwestern University Press, 1974

HAHN, R. Kant's Newtonian Revolution in Philosophy. Carbondale: Southern Illinois University Press, 1988.

HEIJENOORT, J. V. Logic as Calculus and Logic as Language. Synthese, New York: Springer, v. 17, p. 324-330. 1967. 
HERSH, R. What is Mathematics Really? Oxford: Oxford University Press, 1997.

KANT, I. Critique of Pure Reason, second edition. 1787. English translation: Norman Kemp Smith. Edinburgh: MacMillan, 1929.

KLEIN, J. Lectures and Essays, Annapolis: St John's College Press, 1985.

LOCKE, J. An Essay Concerning Human Understanding. New York: Prometheus Books, 1975.

MARKUS, G. Language and Production. Boston Studies in the Philosophy of Science: Kluwer, 1986.

MARTIN, G. Arithmetik und Kombinatorik bei Kant. Berlin: de Gruyter, 1956.

OTTE, M. Mathematical history, philosophy and education, Educational Studies in Mathematics, Springer Netherlands, v. 66, p. 243-255. 2007.

PEIRCE, C. S. CP = Collected Papers of Charles Sanders Peirce, Volumes I-VI, ed. by Charles Hartshorne and Paul Weiss, Cambridge, Mass. (Harvard UP) 1931-1935, Volumes VII-VIII, ed. by Arthur W. Burks, Cambridge, Mass. (Harvard UP) 1958 (quoted by no. of volume and paragraph)

REID, C. Hilbert. Heidelberg: Springer, 1970.

RUSSELL, B. The Analysis of Matter. London: Allan \& Unwin, 1954.

RUSSELL, B. Introduction to Mathematical Philosophy. London: Routledge, 1967.

SKEMP, R. Relational Understanding and Instrumental Understanding, The Arithmetic Teacher, v. 3, p. 9-15. 1978.

THOM, R. Modern Mathematics: Does it Exist?. In: HOWSON, A. G. (Ed.). Developments in Mathematical Education, Cambridge: Cambridge University Press, 1973. p. 194-212.

TURNER, M. The Origin of Ideas. Oxford: Oxford University Press, 2014.

WIENER, N. Pure and applied mathematics. In: HENLE, P. (Ed.). Structure, method and meaning. New York: The Liberal Arts Press, 1951. p. 92.

Submetido em Junho de 2014. Aprovado em Dezembro de 2014. 